\title{
Tribo Olyreae (Poaceae: Bambusoideae) na Ilha de Santa Catarina, Brasil
}

Tribe Olyreae (Poaceae: Bambusoideae) in the Island of Santa Catarina, Brazil

\author{
Thiago Machado Greco ${ }^{1,2}$ \& Ana Zannin ${ }^{1}$
}

\begin{abstract}
Resumo
O trabalho apresenta o levantamento das espécies de Olyreae na Ilha de Santa Catarina, inserida no domínio da Mata Attântica, no litoral do estado de Santa Catarina, sul do Brasil. A tribo compreende os bambus herbáceos e está distribuída nas florestas tropicais e subtropicais, especialmente nos Neotrópicos. É caracterizada por apresentar espiguetas unissexuadas, frequentemente dimórficas, unifloras, sem extensão da ráquila e células epidérmicas com corpos silicosos em forma de cruz na zona costal e crenados na zona intercostal. Foram realizadas coletas entre maio de 2011 e março de 2013. Procedeu-se a análise morfológica de estruturas vegetativas e reprodutivas e a realização de microfotografias de antécios pistilados de coleções de herbário. Foram reconhecidos três gêneros e cinco espécies, todas da subtribo Olyrinae: Olyra glaberrima, O. humilis, $O$. latifolia, Parodiolyra micrantha e Reitzia smithii. A maioria das espécies está presente apenas em alguns pontos da Ilha, em populações reduzidas, em áreas de vegetação mais preservada ou em regeneração. Parodiolyra micrantha é a espécie mais comum e amplamente distribuída na Ilha e Reitzia smithii a de distribuição mais restrita, recoletada após 34 anos no estado de Santa Catarina. São apresentadas descrições, ilustrações, uma chave de identificação e comentários para cada espécie.
\end{abstract}

Palavras-chave: bambus herbáceos, Mata Atlântica, Olyra, Parodiolyra, Reitzia smithii.

\begin{abstract}
This manuscript presents a survey of the species of Olyreae in the Santa Catarina Island, located at the Atlantic Rainforest biome, at the coast of the Santa Catarina state, southern Brazil. The tribe Olyreae comprehends herbaceous bamboos, which are distributed along tropical and subtropical forests, especially in the Neotropics. This tribe is characterized by the presence of unisexual spikelets, usually dimorphic, and 1-flowered with no rachilla extension and epidermal silica cells usually with cross-shaped silica bodies in the coastal zone and crenate in the intercostal zone. Botanical collections were carried out between May 2011 and March 2013. In addition, morphologic analysis of the vegetative and reproductive structures and microphotographs of the female anthecia of herbarium collections were conducted. Three genera and five species were recognized in the study area, all pertaining to the subtribe Olyrinae: Olyra glaberrima, O. humilis, O. latifolia, Parodiolyra micrantha and Reitzia smithii. Most species is only present in small populations in preserved areas or in areas of natural regeneration. Parodiolyra micrantha is the most common and widely distributed species on the Island, while Reitzia smithii is the species with more restricted distribution, collected again after 34 years in the state of Santa Catarina. Descriptions, illustrations, identification key and comments for each species are provided. Key words: herbaceous bamboos, Atlantic Forest, Olyra, Parodiolyra, Reitzia smithii.
\end{abstract}

\section{Introdução}

A tribo Olyreae (Poaceae: Bambusoideae) é composta por 21 gêneros e 127 espécies incluídas em três subtribos, Buergersiochloinae (1 gênero), Parianinae (3 gêneros) e Olyrinae (17 gêneros) (Soreng et al. 2015). As espécies estão distribuídas nas florestas tropicais e subtropicais do planeta, especialmente nos Neotrópicos, entre $29^{\circ} \mathrm{N}$ a $34^{\circ} \mathrm{S}$, não alcançando as regiões temperadas e frias, ou altitudes acima de $1000 \mathrm{~m}$ (Calderón \& Soderstrom 1980; Judziewicz et al. 1999; Zhang \& Clark 2000). No Brasil, país com a maior diversidade da tribo,

\footnotetext{
${ }^{1}$ Universidade Federal de Santa Catarina, Depto. Botânica, Campus Trindade, Florianópolis, 88040-900, SC, Brasil.

${ }^{2}$ Autor para correspondência: thmgreco@gmail.com
} 
está representada por 18 gêneros e cerca de 95 espécies (BFG 2015).

São reconhecidas como sinapomorfias para a tribo a presença de espiguetas unissexuadas (frequentemente dimórficas), unifloras, sem extensão da ráquila, células epidérmicas com corpos silicosos em forma de cruz na zona costal e crenados (oliroides) na zona intercostal (BPG 2012). Seus representantes são plantas de sub-bosque de florestas, intolerantes à radiação direta do sol, rizomatosas (raro sem rizoma), ocasionalmente estoloníferas ou escandentes, entouceirantes, de pequeno a médio porte, com colmos não lignificados, de reduzida ramificação vegetativa, e com espiguetas unissexuadas, distribuídas em diferentes partes na mesma planta (Calderón \& Soderstrom 1980; Judziewicz et al. 1999; Filgueiras \& Santos-Gonçalves 2004). No Brasil, são conhecidas popularmente pelo termo indígena taquari, que significa taquara fina ou de pequeno porte (Filgueiras \& SantosGonçalves 2007).

Os estudos sobre Bambusoideae no estado de Santa Catarina remetem aos trabalhos de McClure \& Smith (1967) e Smith et al. (1981). Posteriormente, alguns novos táxons foram descritos para o estado (Clark 1992; Clark \& Blong 2009; Viana et al. 2013). Para a tribo Olyreae foram referidas cinco espécies para a Ilha de Santa Catarina, quatro sob Olyra e uma para Reitzia. O objetivo deste estudo foi conhecer a atual diversidade da tribo Olyreae na Ilha de Santa Catarina, fornecer meios para a identificação de seus representantes, atualização nomenclatural e informações sobre o status de conservação de cada táxon.

\section{Material e Métodos}

A Ilha de Santa Catarina situa-se no Oceano Atlântico, litoral sul do Brasil, no município de Florianópolis, estado de Santa Catarina, entre as coordenadas geográficas $27^{\circ} 22^{\prime}$ e $27^{\circ} 51^{\prime}$ latitude sul e $48^{\circ} 20^{\prime}$ e $48^{\circ} 37^{\prime}$ longitude oeste, compreendendo cerca de $54 \mathrm{~km}$ de comprimento (norte-sul) e 18 $\mathrm{km}$ de largura (leste-oeste), totalizando $420 \mathrm{~km}^{2}$. A topografia é diversa, variando desde o nível do mar a morros com $532 \mathrm{~m}$ de altitude. Sua vegetação constitui-se em formações do domínio Mata Atlântica, incluindo a Floresta Ombrófila Densa e ecossistemas associados de manguezais, vegetação de restinga, praia, dunas e florestas de planícies quaternárias, caracterizadas como formações vegetais edáficas (Caruso 1990; Horn Filho 2004).
Foram realizadas coletas através de caminhadas aleatórias entre maio de 2011 e março de 2013 e revisadas coleções dos herbários CRI, ESA, FLOR, HBR, MBM, SP e UEC (acrônimos de acordo com Thiers, continuously updated), além de consulta a coleções de herbários virtuais.

Foram coletadas plantas férteis, e eventualmente estéreis, processadas de acordo com Mori et al. (1989) e incorporadas ao herbário FLOR da Universidade Federal de Santa Catarina. A identificação das exsicatas foi feita com base em literatura especializada e por comparação com coleções dos herbários revisados.

Para a obtenção das microfotografias dos antécios pistilados, os mesmos foram montados em stubs, sem pré-tratamento e recobertos com ouro em um metalizador LEICA EM (SCD 500). A observação e captura das imagens foram realizadas com auxílio de microscópio eletrônico de varredura JEOL (JSM-6390LV) no Laboratório Central de Microscopia Eletrônica (LCME) da Universidade Federal de Santa Catarina (UFSC).

A terminologia para indumento e forma seguiu principalmente Radford et al. (1974), Hickey \& King (2000) e Beentje (2010). Dados sobre período de florescimento e habitats preferenciais estão de acordo com as etiquetas de herbários e observações em campo, os de distribuição geográfica geral, de acordo com a literatura e nomes populares e usos com base em literatura, observações pessoais e informações de moradores. No material selecionado, a abreviatura st. indica material estéril e fl. material fértil.

\section{Resultados e Discussão}

A tribo Olyreae está representada na Ilha de Santa Catarina por três gêneros e cinco espécies pertencentes à subtribo Olyrinae: Olyra glaberrima Raddi, Olyra humilis Nees, Olyra latifolia L., Parodiolyra micrantha (Kunth) Davidse \& Zuloaga e Reitzia smithii Swallen. Embora o número de espécies constatadas para a Ilha de Santa Catarina corresponda exatamente ao mesmo levantado por Smith et al. (1981), observou-se que a maioria delas está presente apenas em alguns pontos da Ilha e em populações bem reduzidas, em área de vegetação mais preservada ou em estado de regeneração, sendo a ocupação atual desordenada da Ilha, com consequente diminuição de ambientes sombreados, uma ameaça para as espécies. Informações prévias sobre o tamanho das populações das espécies estudadas não foram mencionadas na literatura consultada. 


\section{Chave para identificação das espécies da tribo Olyreae da Ilha de Santa Catarina}

1. Plantas 0,13-0,31 m alt.; antécio pistilado com manchas escuras na maturidade, com aspecto zebrado; sinflorescências racemosas, contraídas, terminais, raro axilares, parcialmente incluídas nas bainhas na maturidade.

5. Reitzia smithii

1'. Plantas 0,29-4 m alt.; antécio pistilado sem manchas escuras na maturidade; sinflorescências paniculadas, laxas, abertas a subcontraídas, terminais e/ou axilares, exsertas na maturidade .....

2. Antécio pistilado foveolado; pedicelos filiformes nas espiguetas pistiladas e estaminadas; ráquila espessada entre as glumas, conferindo aspecto pulviniforme à base da espigueta; desarticulação abaixo das glumas 4. Parodiolyra micrantha

2'. Antécio pistilado liso (às vezes transversalmente rugoso na mesma planta); pedicelos clavados nas espiguetas pistiladas e filiformes nas estaminadas; ráquila inconspícua entre as glumas, base da espigueta sem aspecto pulviniforme; desarticulação acima das glumas ...

3. Lema do antécio pistilado glabro; diâmetro dos entrenós basais do colmo 4-8 mm; entrenós frequentemente com manchas violáceas; plantas $0,75-2,5 \mathrm{~m}$ alt...... 3. Olyra latifolia

3'. Lema do antécio pistilado parcialmente pubescente; diâmetro dos entrenós basais do colmo 0,7-4 mm; entrenós sem manchas violáceas; plantas 0,29-1 $\mathrm{m}$ alt.

4. Gluma superior da espigueta pistilada aristada; sinflorescências 6,5-7,5 cm compr.; lâminas foliares 4,5-9,5 × 1,3-2,3 cm, face abaxial glauca...... 2. Olyra humilis

4'. Gluma superior da espigueta pistilada aguda; sinflorescências 8,1-14,6 cm compr.; lâminas foliares 7,3-21,3 × 3,1-6,3(-9) cm, face abaxial verde ....1. Olyra glaberrima

1. Olyra glaberrima Raddi, Agrostogr. Bras. 19. 1823.

Figs. 1a-d; 2a-d

Plantas $0,5-1 \mathrm{~m}$ alt., eretas, cespitosorizomatosas, às vezes geniculadas nos nós basais. Rizoma paquimorfo, pescoço curto. Colmos não ramificados, diâmetro basal $2-4 \mathrm{~mm}$; entrenós (1,9-)3,2-25,5(-27,5) cm compr., cilíndricos, verdes, estriados, glabros, extremidades glabras, lúmen conspícuo; linha nodal glabra, violácea (castanha a negra em material herborizado), nós em contato com o solo não radicantes. Bainha (3,6-)4,1-11,8 $(-12,9) \mathrm{cm}$ compr., glabra, margens ciliadas; lígula interna 1-2 mm compr., membranosa com ápice ciliado a ciliolado; pseudopecíolo 1,9-3,8 mm compr., verde a castanho, pubescente em ambas as faces; lâmina foliar 7,3-21,3 × 3,1-6,3(-9) $\mathrm{cm}$, oval-lanceolada, base assimétrica, glabra em ambas as faces, verde, margens glabras ou ciliadas. Sinflorescências 8,1-14,6 × 2,5-7,5 cm, exsertas na maturidade, ramos inferiores verticilados, com numerosas espiguetas estaminadas, com ou sem uma espigueta pistilada terminal e ramos superiores opostos ou alternos, com espiguetas estaminadas inferiores e uma pistilada, ráquis e pedicelos glabros, lisos a escabros. Espiguetas pistiladas fusiformes, glumas maiores que os antécios; gluma I $11-15,1(-17,2) \times 2,2-3,5 \mathrm{~mm}, 5(-7)$-nervada, aristada, verde, às vezes com margens violáceas, glabra, arista escabra; gluma II 7,8-11,1 × 1,9-3,1 $\mathrm{mm}, 5(-7)$-nervada, aguda, verde, às vezes com margens violáceas, glabra, ápice escabro; antécio não estipitado, liso, sem manchas escuras na maturidade; lema 6,2-7,9 × 1,9-3,2 mm, 5-nervado, verde a esbranquiçado, liso, com base e ápice densamente pubescentes, tricomas brancos a prateados; pálea 5,8-7,1 mm compr., 2-nervada, verde a esbranquiçada, lisa, glabra; lodículas lisas, glabras; estigmas brancos a castanhos; ovário branco a castanho, glabro, liso; cariopse 4,8 $\times 1$ $\mathrm{mm}$. Espiguetas estaminadas: lema $(4,3-) 6,7-$ 9,6(-11,4) mm compr., 3-nervado, aristado, hialino a castanho, com manchas violáceas e nervuras verdes, glabro, liso ou brevemente escabro, arista violácea, escabra; pálea $(4,2-) 5,2-7,1(-7,9) \mathrm{mm}$ compr., 2-nervada, acuminada, hialina a castanha, com manchas violáceas e nervuras verdes, glabra, lisa, ápice escabro; anteras 3,5-5,3 $\mathrm{mm}$ compr., amareladas a castanhas.

Material selecionado: Florianópolis, Ilha de Santa Catarina, Trilha do Saquinho, 12.I.2012, fl., T. Greco \& A. Zannin 64 (FLOR).

Olyra glaberrima apresenta distribuição disjunta entre o México, América Central (Belize, Guatemala e Honduras), sul do Peru, leste do Brasil (Soderstrom \& Zuloaga 1989) e Paraguai (Ohrnberger 1999). No Brasil, há registros para Bahia, Distrito Federal, Espírito Santo, Pernambuco, Rio de Janeiro, São Paulo, Paraná, Rio Grande do Sul e Santa Catarina, no domínio da Mata Atlântica (BFG 2015). 


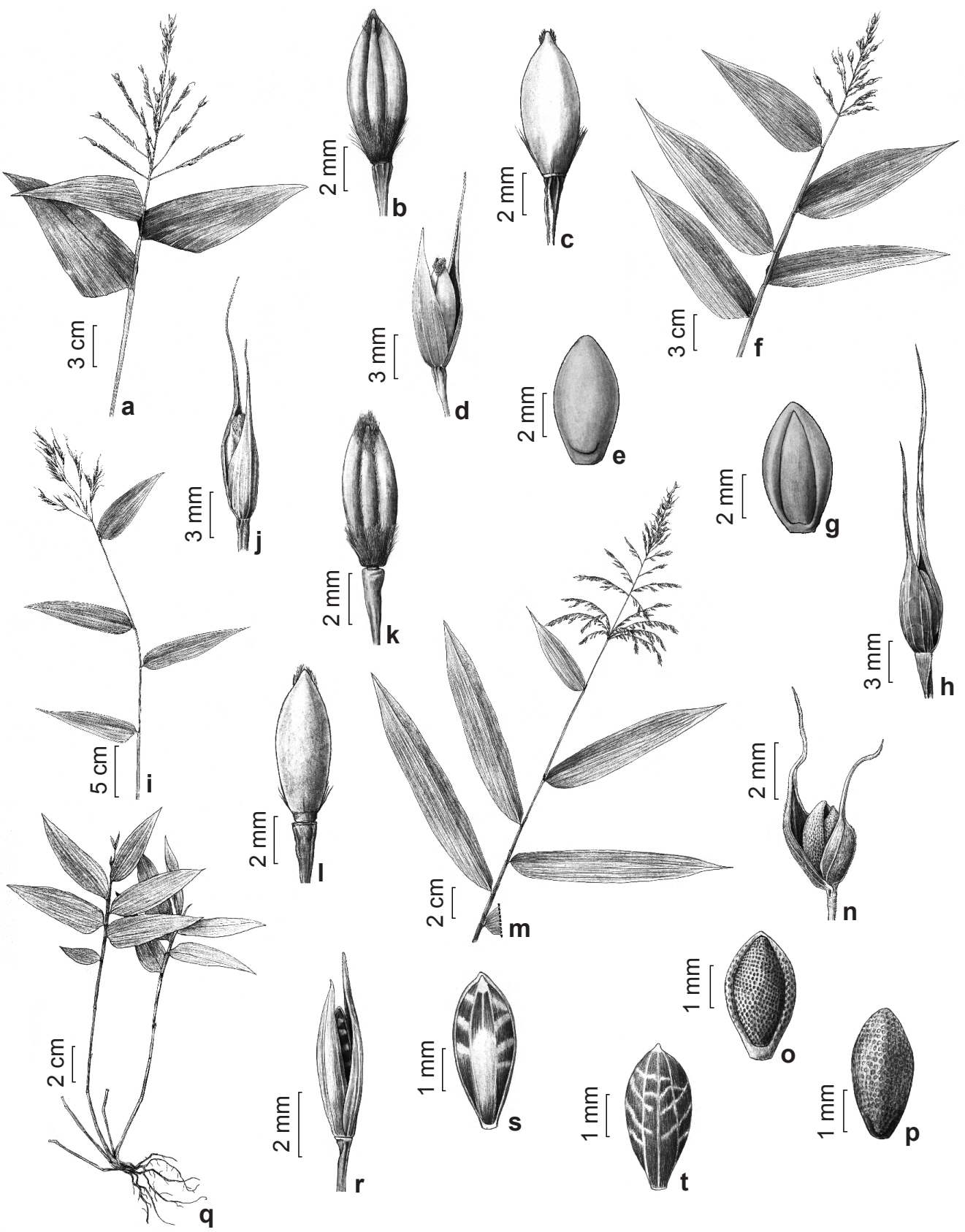

Figura 1 - a-d. Olyra glaberrima - a. fragmento do colmo florífero; b. antécio pistilado, vista ventral; c. antécio pistilado, vista dorsal; d. espigueta pistilada (T. Greco \& A. Zannin 64). e-h. Olyra latifolia - e. antécio pistilado, vista dorsal; f. fragmento do colmo florífero; g. antécio pistilado, vista ventral; h. espigueta pistilada (T. Greco 23). i-1. Olyra humilis - i. fragmento do colmo florífero; j. espigueta pistilada; k. antécio pistilado, vista ventral; 1. antécio pistilado, vista dorsal (T. Greco 135). m-p. Parodiolyra micrantha - m. fragmento do colmo florífero; $n$. espigueta pistilada; o. antécio pistilado, vista ventral; $\mathrm{p}$. antécio pistilado, vista dorsal (T. Greco \& R.E. Ardissone 11). q-t. Reitzia smithii-q. hábito; r. espigueta pistilada; s. antécio pistilado, vista ventral; t. antécio pistilado, vista dorsal (T. Greco 120).

Figure 1 - a-d. Olyra glaberrima - a. fragment of floriferous culm; b. female anthecium, ventral side; c. female anthecium, dorsal side; d. female spikelet (T. Greco \& A. Zannin 64). e-h. Olyra latifolia - e. female anthecium, dorsal side; f. fragment of floriferous culm; g. female anthecium, ventral side; h. female spikelet (T. Greco 23). i-1. Olyra humilis - i. fragment of floriferous culm; j. female spikelet; k. female anthecium, ventral side; 1. female anthecium, dorsal side (T. Greco 135). m-p. Parodiolyra micrantha - m. fragment of floriferous culm; n. female spikelet; o. female anthecium, ventral side; p. female anthecium, dorsal side (T. Greco \& R.E. Ardissone 11). q-t. Reitzia smithii -q. habit; r. female spikelet; s. female anthecium, ventral side; t. female anthecium, dorsal side (T. Greco 120). 
Na Ilha de Santa Catarina é relativamente rara, encontrada em áreas sombreadas de subbosque e encostas pouco íngremes de formações secundárias da Floresta Ombrófila Densa do leste e sul da Ilha, em pequenas populações.

Olyra glaberrima assemelha-se a O. humilis, compartilhando diversas características, incluindo o lema do antécio pistilado com base e ápice marginais densamente pubescentes. O. glaberrima, no entanto, apresenta plantas mais robustas, com colmos floríferos mais longos e sinflorescências e folhas maiores (bainhas e pseudopecíolos mais longos, lâminas foliares mais longas e largas). Além do porte, a separação das duas espécies no campo é auxiliada pela presença de linha nodal engrossada, proeminente, de coloração violácea em $O$. glaberrima e pela coloração glauca da face abaxial das lâminas foliares em $O$. humilis (muitas vezes visível também em exsicata).

Devido à beleza de suas folhas e sinflorescências, a espécie poderia ser cultivada como planta ornamental em vasos para interiores. $\mathrm{O}$ epíteto "glaberrima" é uma alusão à característica glabra das lâminas foliares (Smith et al. 1981), podendo, entretanto, ser ciliadas nas margens de acordo material estudado. Coletada com flores e/ ou frutos nos meses de dezembro, janeiro e março.

2. Olyra humilis Nees, Fl. Bras. Enum. Pl. 2(1): 304-306. 1829.

Figs. 1i-l; 2e-h

Plantas 0,29-0,55 m alt., eretas na base e arqueadas no ápice, cespitoso-rizomatosas, às vezes geniculadas nos nós basais. Rizoma paquimorfo, pescoço curto. Colmos não ramificados, diâmetro basal $0,7-1,5 \mathrm{~mm}$; entrenós $(2,7-) 3,8-8,8(-13,2) \mathrm{cm}$ compr., cilíndricos, verdes, estriados, glabros, extremidades pubérulas, lúmen conspícuo; linha nodal glabra, castanha a negra, nós em contato com o solo não radicantes. Folhas de ramo: bainha $(2,4-) 3-4,8(-6,4) \mathrm{cm}$ compr., glabra a pubérula, margens ciliadas; lígula interna $0,3-1 \mathrm{~mm}$ compr., membranosa com ápice ciliado a ciliolado; pseudopecíolo 0,9-1,2 mm compr., castanho, pubescente em ambas as faces; lâmina foliar 4,5-9,5 × 1,3-2,3 $\mathrm{cm}$, lanceolada, base assimétrica, glabra na face adaxial, glabra a pubérula na face abaxial, face adaxial verde e abaxial glauca, margens escabras. Sinflorescências $6,5-7,5 \times 1,8-2,3 \mathrm{~cm}$, exsertas na maturidade, ramos inferiores verticilados, opostos ou alternos, superiores alternos, todos os ramos com numerosas espiguetas inferiores estaminadas e uma pistilada terminal, ráquis e pedicelos glabros, lisos a escabros. Espiguetas pistiladas fusiformes, glumas maiores que os antécios; gluma I $(15,2-) 17,3-20 \times 2-2,6(-3,1)$ $\mathrm{mm}, 5$-nervada, aristada, verde a castanha, às vezes com margens violáceas, glabra, arista escabra; gluma II $10-12,3 \times 2,3-3,1 \mathrm{~mm}$, 5-nervada, aristada, verde a castanha, glabra, arista lisa; antécio não estipitado, liso, sem manchas escuras na maturidade; lema 6,1-6,8 $\mathrm{mm}$ compr., 5-nervado, branco a castanho, liso, densamente pubescente na base, margens e ápice, tricomas brancos a castanhos; pálea 5,1-5,9 mm compr., 2-nervada, branca a castanha, lisa, glabra a pubescente no ápice; lodículas lisas, glabras; estigmas brancos a castanhos; ovário branco a castanho, glabro, liso; cariopse 4,3 $\times$ 1,9 mm. Espiguetas estaminadas: lema 7,9-12,1 mm compr., 3-nervado, aristado, hialino, com manchas violáceas e nervuras verdes, glabro, liso ou brevemente escabro, arista violácea, escabra; pálea 5,8-8,1 mm compr., 2-nervada, acuminada, hialina, com manchas violáceas e nervuras verdes, glabra, lisa, ápice escabro; anteras 3,5-5,7 $\mathrm{mm}$ compr., amareladas a castanho-escuras.

Material selecionado: Florianópolis, Ilha de Santa Catarina, Lagoinha do Leste, 2.XI.2012, fl., T. Greco 138 (FLOR).

Olyra humilis ocorre na porção noroeste da Argentina, Paraguai e Brasil (Soderstrom \& Zuloaga 1989; Ohrnberger 1999). No Brasil, possui registro para Bahia, Distrito Federal, Espírito Santo, Goiás, Maranhão, Minas Gerais, Piauí, Paraná, Rio de Janeiro, Rio Grande do Sul, São Paulo e Santa Catarina (BFG 2015) nos domínios da Caatinga, Cerrado e Mata Atlântica. Na Ilha de Santa Catarina ocorre predominantemente em margens de trilhas e próximo de cursos d'água em formações secundárias de Floresta Ombrófila Densa e, mais raramente, em solos arenosos de restinga, do nível do mar a $300 \mathrm{~m}$ de altitude, no norte e sul da Ilha.

Olyra humilis é reconhecida especialmente pelo lema do antécio pistilado pubescente na base, nas margens e ápice e pelo porte distintamente delicado, advindo do menor comprimento do colmo florífero (que alcança $0,55 \mathrm{~m}$ alt.) e das menores dimensões das lâminas foliares e sinflorescências, em comparação com as demais espécies do gênero na Ilha. Destaca-se também pela face abaxial da lâmina foliar glauca entre as espécies estudadas. Assemelha-se a $O$. glaberrima, diferenciando-se por caracteres já referidos nos comentários desta espécie. 


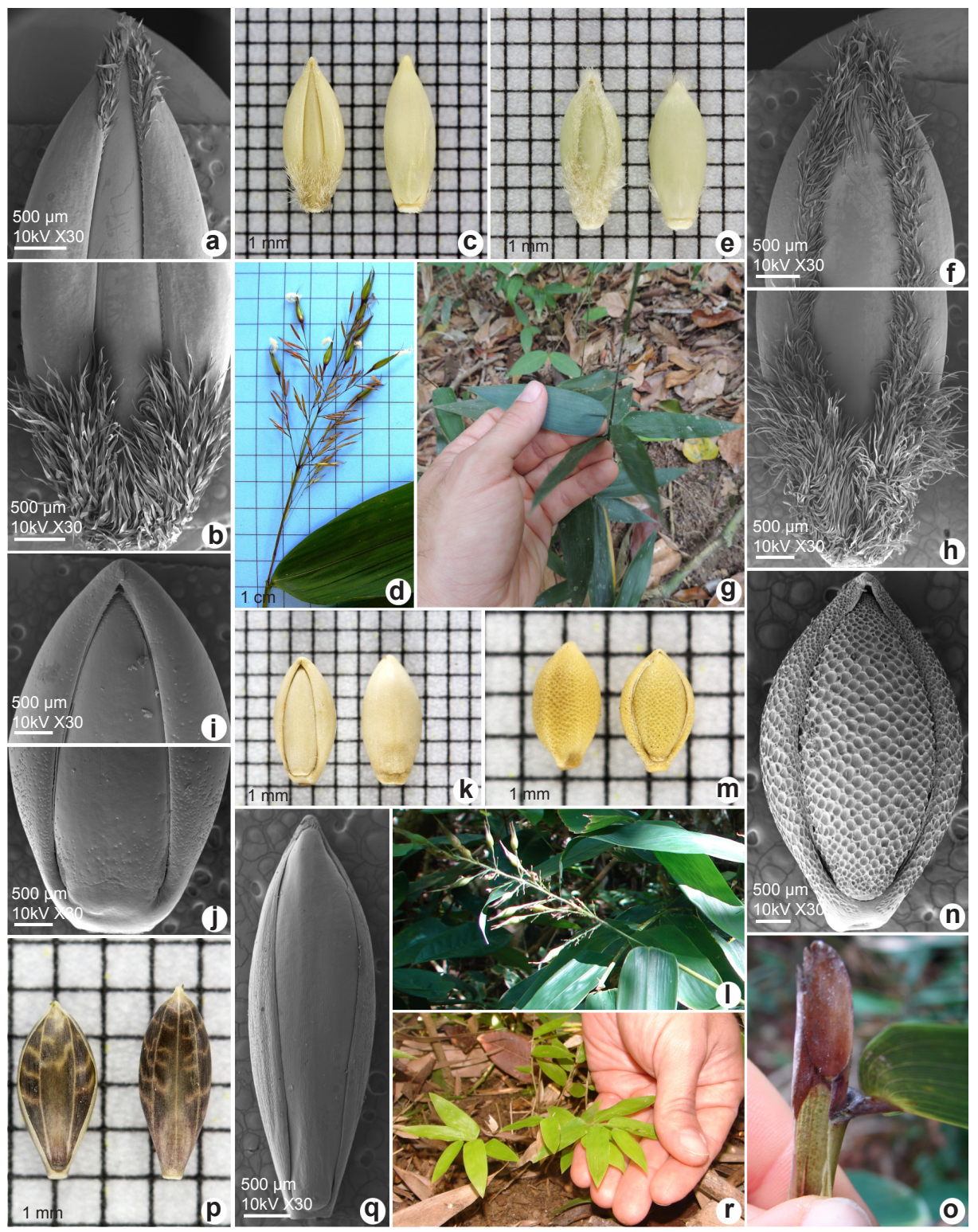

Figura 2 - a-d. Olyra glaberrima - a. antécio pistilado em MEV, ápice, vista ventral; b. antécio pistilado em MEV, base, vista ventral (T. Greco \& A. Zannin 64); c. antécio pistilado, vista ventral (esquerda) e vista dorsal (direita); d. ápice do colmo florífero. e-h. Olyra humilis - e. antécio pistilado, vista ventral (esquerda) e vista dorsal (direita); f. antécio pistilado em MEV, ápice, vista ventral (T. Greco 135); g. porção do colmo, evidenciando lâmina com face abaxial glauca; h. antécio pistilado em MEV, base, vista ventral (T. Greco 135). i-l. Olyra latifolia - i. antécio pistilado em MEV, ápice, vista ventral; j. antécio pistilado em MEV, base, vista ventral (T. Greco 163); k. antécio pistilado, vista ventral (esquerda) e vista dorsal (direita); 1. lâminas foliares e sinflorescência. m-o. Parodiolyra micranta - m. antécio pistilado, vista dorsal (esquerda) e vista ventral (direita); n. antécio pistilado em MEV, vista ventral (T. Greco \& R.E. Ardissone 11); o. porção da folha, evidenciando lígula interna. p-r. Reitzia smithii - p. antécio pistilado, vista ventral (esquerda) e vista dorsal (direita); q. antécio pistilado em MEV, vista ventral (T. Greco 120); r. hábito, na natureza.

Figure 2 - a-d. Olyra glaberrima. a. ventral side of the female anthecium apex; b. ventral side of the female anthecium base (T. Greco \& A. Zannin 64); c. female anthecium ventral side (left) and dorsal side (right); d. floriferous culm apex. e-h. Olyra humilis - e. female anthecium ventral side (left) and dorsal side (right); f. ventral side of the female anthecium apex (T. Greco 135); g. culm section, showing the leaf blade glaucous abaxial surface; $h$. ventral side of the female anthecium base (T. Greco 135). i-l. Olyra latifolia -i. ventral side of the female anthecium apex; j. ventral side of the female anthecium base (T. Greco 163); k. female anthecium ventral side (left) and dorsal side (right); 1. leaf blades and inflorescences. m-o. Parodiolyra micranta $-\mathrm{m}$. female anthecium dorsal side (left) and ventral side (right); $\mathrm{n}$. ventral side of the female anthecium (T. Greco \& R.E. Ardissone 11); o. leaf section showing the internal ligule. p-r. Reitzia smithii - p. female anthecium ventral side (left) and dorsal side (right); q. ventral side of the female anthecium; r. habit, live plant (T. Greco 120). 
Assim como O. glaberrima, a espécie apresenta grande potencial ornamental. $\mathrm{O}$ epíteto "humilis" significa baixo, em alusão ao pequeno porte das plantas. Coletada com flores e/ou frutos de agosto a dezembro.

3. Olyra latifolia L., Syst. Nat., ed. 10, 2: 1261. 1759.

Figs. 1e-h; 2i-1

Plantas 0,75-2,5 m alt., eretas ou apoiantes, cespitoso-rizomatosas. Rizoma paquimorfo, pescoço curto. Colmos ramificados ou não nos nós superiores, diâmetro basal 4-8 $\mathrm{mm}$; entrenós $(2,8-) 4,2-30,8(-35,5) \mathrm{cm}$ compr., cilíndricos, verdes, frequentemente com manchas violáceas, estriados, glabros, extremidades pubérulas a pubescentes, lúmen conspícuo; linha nodal glabra a pubérula, verde a negra, nós em contato com o solo eventualmente radicantes. Folhas de ramo: bainha $(4-) 4,5-11,8(-13,4) \mathrm{cm}$ compr., hirsuta quando jovem, tricomas caducos, margens glabras ou ciliadas; lígula interna $1-1,5 \mathrm{~mm}$ compr., membranosa, com ou sem cílios no ápice; pseudopecíolo 1,9-5,8 mm compr., castanho, face adaxial glabra a pubérula, face abaxial pubérula a pubescente; lâmina foliar $(2,3-) 4,6-23,6 \times$ $1-6,4(-7,1) \mathrm{cm}$, oval-lanceolada, base assimétrica, glabra em ambas as faces e margens, verde. Sinflorescências 8,5-18,3 × 1,5-6 cm, exsertas na maturidade, ramos inferiores subverticilados com numerosas espiguetas estaminadas, com ou sem pistiladas terminais, ramos superiores alternos com poucas espiguetas estaminadas na porção inferior e uma ou mais espiguetas pistiladas terminais, ráquis e pedicelos pubérulos a pubescentes. Espiguetas pistiladas oval-lanceoladas a ovais, glumas maiores que os antécios; gluma I $(11,2-) 12,1-20,1(-23,1) \times 2,1-3,2(-3,9) \mathrm{mm}$, 7-10-nervada, aristada, verde a castanha, glabra, arista escabra; gluma II 8,0-12,1 × 1,9-3,8 mm, 7-8-nervada, aristada, verde a castanha, glabra, arista escabra; antécio não estipitado, liso, às vezes transversalmente rugoso na mesma planta, sem manchas escuras na maturidade; lema 4,8-6,1 mm compr., esbranquiçado, glabro, geralmente liso, nervuras inconspícuas; pálea 4,2-5,5 mm compr., esbranquiçada, glabra, lisa, nervuras inconspícuas; lodículas lisas, glabras; estigmas esbranquiçados; ovário castanho, glabro, liso; cariopse 3,8-3,9 $\times$ $1,7 \mathrm{~mm}$. Espiguetas estaminadas: lema 3,4-7,5 mm compr., 3-4-nervado, aristado, verde a verdevioláceo, glabro, liso ou brevemente escabro, arista violácea, escabra; pálea (2,7-)3,2-5,1 mm compr., 2-nervada, glabra, verde a verde-violácea; anteras
0,9-3 mm compr., amareladas a castanho-escuras. Material selecionado: Florianópolis, Ilha de Santa Catarina, Trilha do Saquinho, 12.I.2012, fl. e fr., T. Greco \& A. Zannin 63 (FLOR).

Olyra latifolia é o bambu herbáceo de distribuição mais ampla no planeta, ocorrendo na região Neotropical, desde a Flórida (EUA), América Central e Caribe, até a América do Sul (Venezuela, Colômbia, Equador, Suriname, Guiana, Guiana Francesa, Peru, Bolívia, Paraguai, Argentina e Brasil) (Ohrnberger 1999) e com registro também para a África tropical e Ilha de Madagascar, onde provavelmente foi introduzida (Judziewicz et al. 1999). No Brasil, está presente nos domínios fitogeográficos da Amazônia, Caatinga, Cerrado e Mata Atlântica, com registros para os estados do Acre, Alagoas, Amazonas, Amapá, Bahia, Ceará, Distrito Federal, Espírito Santo, Goiás, Maranhão, Mato Grosso, Mato Grosso do Sul, Minas Gerais, Pará, Paraíba, Paraná, Pernambuco, Rio de Janeiro, Rio Grande do Sul, Rondônia, Roraima, São Paulo, Sergipe, Tocantins e Santa Catarina (BFG 2015). Na Ilha de Santa Catarina é uma espécie pouco frequente, encontrada no sub-bosque de Floresta Ombrófila Densa em estágio secundário de desenvolvimento, bordas de fragmentos florestais e locais sombreados de margens de trilhas e riachos, no leste, norte e sul da Ilha, em altitudes ente 10 e $200 \mathrm{~m}$.

Olyra latifolia pode ser reconhecida pelo antécio pistilado esbranquiçado, geralmente liso e completamente glabro, diferente das outras espécies ocorrentes na Ilha, nas quais o lema do antécio pistilado é ventralmente pubescente nas margens e/ou ápice e base. Além disso, O. latifolia apresenta plantas significativamente mais altas e robustas que as demais, podendo atingir $2,5 \mathrm{~m}$ de altura (em outros países até $6 \mathrm{~m}$ alt.) (Ohrnberger 1999); e possuir o dobro do diâmetro basal máximo dos colmos de $O$. glaberrima ( $8 \mathrm{~mm}$ versus $4 \mathrm{~mm}$ ) e cerca de cinco vezes mais que $O$. humilis $(8 \mathrm{~mm}$ versus $1,5 \mathrm{~mm}$ ).

Alguns caracteres poucas vezes observados em material herborizado são marcantes nas plantas recém-coletadas e em campo, como a presença de tricomas nas bainhas das folhas e manchas violáceas nos entrenós, especialmente nos inferiores, permitindo às vezes identificar a espécie mesmo em fase estéril.

Foram observadas em alguns indivíduos de $O$. latifolia, ramificações nos nós superiores e enraizamento nos nós quando em contato com o solo, atributos também apresentados por Parodiolyra micrantha. 
O epíteto "latifolia" provém do latim latus (largo) e folia (folhas), sendo uma alusão à largura das lâminas foliares (Smith et al. 1981). É popularmente conhecida por taquara, taquarimole (BFG 2015). No Peru, onde é utilizada como matéria prima para a confecção de flautas (Judziewicz et al. 1999), é chamada de pito. Coletada com flores e/ou frutos de novembro a janeiro e março.

4. Parodiolyra micrantha (Kunth) Davidse \& Zuloaga, Novon 9: 590. 1999.

Figs. 1m-p; $2 \mathrm{~m}-\mathrm{o}$

Plantas 1-4 m alt., eretas na base e arqueadas no ápice, cespitoso-rizomatosas. Colmos com ou sem ramificações, diâmetro basal 4-9 mm; entrenós $(4,2-) 6,6-14(-20) \mathrm{cm}$ compr., cilíndricos, verdes a castanhos, estriados, glabros, extremidades glabras, lúmen conspícuo; linha nodal glabra, castanha, nós em contato com o solo radicantes. Folhas de ramo: bainha (4,3-)5,7-11,9 cm compr., glabra, margens ciliadas; lígula interna 5-20 mm compr., membranosa ou membranoso-ciliolada, fusionada lateralmente a uma das margens da bainha e envolvendo o colmo, frequentemente assimétrica; pseudopecíolo 2,2-6 $\mathrm{mm}$ compr., verde a castanho-escuro, glabro em ambas as faces, raro curto piloso na face adaxial; lâmina foliar $(9,6-) 10,5-24,6(-27,4) \times(1,5-) 2,4-6(-6,4)$ $\mathrm{cm}$, lanceolada, base levemente assimétrica, arredondada, glabra em ambas as faces, verde, margens escabras. Sinflorescências (8,3-)13,1-21 $\times(2,5-) 3,5-8,3(-9) \mathrm{cm}$, exsertas na maturidade, ramos basais verticilados ou alternos apenas com espiguetas estaminadas, ramos superiores alternos somente com espiguetas pistiladas ou, raramente, estaminadas na base e pistiladas terminais, ráquis e pedicelos pubérulos ou densamente pubescentes, escabros. Espiguetas pistiladas ovais a elípticas, glumas maiores que os antécios; gluma I 6,5-9,4 × 1,9-2,6 mm, 4-5-nervada, aristada a subulada, verde a castanha, pubérula a pubescente, arista escabra; gluma II (4,1-)4,9-5,9 $\times 1,6-2,3 \mathrm{~mm}, 3$-nervada, aristada a subulada, verde a castanho-escura, pubérula a pubescente, arista escabra; antécio não estipitado, foveolado, sem manchas escuras na maturidade; lema 2,8-3,6 $\times(0,9-) 1,2-1,9 \mathrm{~mm}, 5$-nervado, esbranquiçado a castanho, foveolado, ovoide; pálea 2,4-2,7 mm compr., 2-nervada, esbranquiçada a castanha, foveolada; lodículas glabras, lisas, esbranquiçadas a hialinas; estigmas brancos, plumosos; ovário branco a castanho, glabro, liso. Cariopse 1,9-2,2 $\times$ 0,9-1,3 mm, castanha, ovoide, glabra; hilo linear, $3 / 4$ do comprimento da cariopse. Espiguetas estaminadas: lema 6,2-7,8 mm compr., 3-nervado, hialino a castanho, às vezes com pigmentações violáceas, glabro, liso a escabro, aristado, arista escabra, nervuras verdes a castanhas, com ou sem escabrosidades; pálea 4,5-5,5 $\mathrm{mm}$ compr., 2-nervada, acuminada, hialina a castanha, às vezes com pigmentações violáceas, lisa a escabra, acuminada, nervuras verdes a castanhas, com ou sem escabrosidades; anteras $(2,2-) 3,2-4,1 \mathrm{~mm}$ compr., castanhas.

Material selecionado: Florianópolis, Ilha de Santa Catarina, Córrego Grande, Parque Municipal do Córrego Grande, 28.IX.2011, fl., T. Greco \& R.E. Ardissone 11 (FLOR).

Parodiolyra micrantha é uma espécie sul-americana, presente na Argentina, Bolívia, Brasil, Colômbia, Peru, Paraguai, Venezuela e Guianas (Smith et al. 1981; Ohrnberger 1999) e com registro também para as Ilhas Fiji, onde provavelmente foi introduzida (Ohrnberger 1999). No Brasil, apresenta ampla distribuição, com citação para todas as regiões, especialmente para os domínios fitogeográficos da Amazônia, Caatinga, Cerrado e Mata Atlântica (BFG 2015).

$\mathrm{Na}$ Ilha de Santa Catarina é a espécie mais comum de Olyreae, ocorrendo em bordas sombreadas de fragmentos de mata secundária, margens de trilhas e riachos e, em raras situações, crescendo a pleno sol em áreas degradadas, especialmente em topos de morros. É amplamente distribuída em áreas de condições favoráveis do norte ao sul da Ilha, entre 100 e $300 \mathrm{~m}$ de altitude.

Parodiolyra micrantha pode ser reconhecida especialmente pela superfície foveolada do antécio pistilado e pela peculiar lígula interna, muito conspícua atingindo $20 \mathrm{~mm}$ compr., fusionada lateralmente a uma das margens da bainha. Os colmos das plantas dessa espécie crescem e se arqueiam na região apical e seguem em processo de crescimento até tocarem o solo, já que a base do colmo não suporta mais o próprio peso. Em contato com o solo, os colmos enraízam na região dos nós, dando origem a novas plantas. Essa estratégia de propagação pode explicar a formação de grandes e densos aglomerados.

Parodiolyra micrantha assemelha-se vegetativamente a Olyra latifolia, na altura da planta, dimensões da lâmina foliar e diâmetro basal dos colmos, e por ambas apresentarem frequentemente ramificações nos nós superiores e nós radicantes quando em contato com o solo. 
Diferem principalmente pela superfície do antécio pistilado, foveolada em $P$. micrantha e lisa (menos frequentemente rugoso na mesma planta) em O. latifolia.

O epíteto "micrantha" provém do grego "micros" (pequeno) e "anthos" (flor) em referência às espiguetas relativamente pequenas (Smith et al. 1981). Devido à tolerância a exposição direta ao sol, poderia ser recomendado seu uso em projetos de recuperação de áreas degradadas (Shirasuna \& Filgueiras 2013). Coletada com flores e/ou frutos de julho a dezembro e de fevereiro a abril.

\section{Reitzia smithii Swallen, Sellowia 7: 8.1956.}

Figs. 1q-t; 2p-r

Plantas $(0,13-) 0,17-0,31 \mathrm{~m}$ alt., cespitosas, em geral fortemente geniculadas nos nós basais. Colmos não ramificados, diâmetro basal $0,5-1$ $\mathrm{mm}$; entrenós 1,5-6,5 cm compr., cilíndricos, verdes a castanhos, estriados, glabros, apenas com uma linha longitudinal pubérula, extremidades glabras a pubérulas, lúmen conspícuo; linha nodal pubérula a densamente pubescente, verde a negra, tricomas alvos, nós em contato com o solo não radicantes. Folhas de ramo: bainha $1,1-2,5 \mathrm{~cm}$ compr., glabra a pubérula, margens e submargens ciliadas; lígula interna $0,3-0,5 \mathrm{~mm}$ compr., membranoso-ciliolada; pseudopecíolo 0,6-1,7 mm compr., castanho-claro, pubérulo a pubescente em ambas as faces; lâmina foliar $2,2-7,4 \times 0,9-1,5 \mathrm{~cm}$, oval-lanceolada, base levemente assimétrica, puberulenta, com ou sem alguns tricomas maiores esparsos, em ambas as faces, verde, margens escabras. Sinflorescências 1,4-2,6 × 0,2-0,4 cm, parcialmente incluídas nas bainhas, terminais, raro axilares, ráquis curtamente pubescente e pedicelos levemente escabros. Espiguetas pistiladas lanceoladas, glumas maiores que os antécios; gluma I 5-7,1 × 1,2-2,1 mm, 3-5-nervada, acuminada, verde a castanho-clara, região apical glabra a pubérula nas margens, ápice escabro; gluma II 5,1-6,1 × 1,1-1,9 mm, 3 -nervada, acuminada, verde a castanho-clara, glabra, ápice escabro; antécio liso, com manchas escuras na maturidade, conferindo-lhe aspecto zebrado; lema 3,7-5,1 × 0,9-2 mm, 3-5-nervado, verde-oliváceo quando jovem, com manchas escuras na maturidade, oblanceolado, liso, glabro; pálea 3,6-4,9 × 0,8-2 mm, 2-nervada, sobreposta pelo lema nas margens, verde-olivácea quando jovem, com manchas escuras na maturidade, lisa, glabra; lodículas lisas, glabras, esbranquiçadas; estigmas brancos, plumosos; ovário esverdeado, liso, glabro. Cariopse 3,2-4,1 × 1,2 mm. Espiguetas estaminadas: lema 3-3,1 mm compr., 3-nervado, acuminado, verde a castanho-claro, glabro, liso, apenas ápice escabro; pálea 2,6-2,9 mm compr., 2-nervada, acuminada, verde a castanha, glabra, lisa, apenas ápice escabro; anteras 1-1,3 mm compr., esbranquiçadas a amareladas.

Material selecionado: Florianópolis, Ilha de Santa Catarina, Ribeirão da Ilha, Morro do Ribeirão, 6.VII.2012, fl., T. Greco 126 (FLOR).

Reitzia smithii é endêmica do Brasil, presente nos estados do Rio de Janeiro, São Paulo e Santa Catarina (BFG 2015). É a espécie de distribuição mais restrita na Ilha, recoletada após 34 anos no estado de Santa Catarina. Silva et al. (2012) destacaram o baixo número de coletas desta espécie no Brasil, citando-a como ainda com dados deficientes (DD) de acordo com critérios da IUCN (International Union for Conservation of Nature).

Na Ilha de Santa Catarina apresenta registros apenas para três localidades: Ribeirão da Ilha, Saco Grande e Trindade, sendo que as coletas das duas últimas localidades datam de 1966 e 1978, respectivamente. Foi encontrada durante este estudo apenas em uma área bem preservada de Floresta Ombrófila Densa no sul da Ilha (Morro do Ribeirão), em ambientes sombreados de solo úmido, em beira de riacho ou várzeas no interior da floresta, formando densos agrupamentos descontínuos.

R. smithii pode ser reconhecida pelo seu porte reduzido (até $0,31 \mathrm{~m}$ alt.), colmos frequentemente geniculados nos nós basais e antécio pistilado com manchas escuras (no lema e pálea), conferindolhe aspecto zebrado na maturidade. Além disso, apresenta sinflorescências racemosas com espiguetas aos pares, uma subsséssil estaminada e outra pedicelada pistilada, parcialmente incluídas nas bainhas, dando a impressão à primeira vista de as plantas encontrarem-se estéreis mesmo em estágio fértil, quando observadas no campo.

A presença de manchas escuras no antécio pistilado maduro foi referida por outros autores para algumas espécies de Olyra e/ou Raddia (Soderstrom \& Zuloaga 1989; Silva et al. 2012; Shirasuna \& Filgueiras 2013). No material estudado, só foram observadas em Reitzia, sendo, portanto, utilizadas como um caráter diagnóstico auxiliar para reconhecimento do gênero, conforme também Calderón \& Soderstrom (1980). Porém, cabe ressaltar que nas microfotografias estas manchas não aparecem, provavelmente ocultadas pelo recobrimento em ouro. 
A espécie tem grande potencial ornamental para uso como planta de forração em áreas de sombra. A atual distribuição restrita na Ilha, como em outras regiões do Brasil (Silva et al. 2012), provavelmente é reflexo da degradação dos ambientes naturais da espécie. O nome genérico Reitzia é uma homenagem ao Padre Dr. Raulino Reitz (1919-1990), importante botânico catarinense. O epíteto smithii é uma homenagem ao botanist emeritus estadunidense, Lyman Bradford Smith (1904-1997), pesquisador da flora catarinense. Coletada com flores e/ou frutos nos meses de janeiro, maio, julho, setembro e novembro.

\section{Agradecimentos}

À Capes, a bolsa de Mestrado concedida ao primeiro autor. Aos curadores dos herbários citados. Ao Biólogo Leandro Lopes, a confecção das ilustrações. Aos técnicos do Laboratório Central de Microscopia Eletrônica (LCME) da UFSC, o apoio na obtenção das microfotografias.

\section{Referências}

Beentje, H.J. 2010. The Kew plant glossary: an illustrated dictionary of plant terms. Royal Botanic Gardens, Londres. 160p.

BFG. 2015. Growing knowledge: an overview of seed plant diversity in Brazil. Rodriguésia 66: 1085-1113.

BPG (Bamboo Phylogeny Group) 2012. An updated tribal and subtribal classification of the bamboos (Poaceae: Bambusoideae). Bamboo Science and Culture: The Journal of the American Bamboo Society 24: 1-10.

Calderón, C.E. \& Soderstrom, T.R. 1980. The genera of Bambusoideae (Poaceae) of the American continent: keys and comments. Smithsonian Contributions to Botany 44: 1-27.

Caruso, M.M.L. 1990. O desmatamento da Ilha de Santa Catarina de 1500 aos dias atuais. 2a ed. Editora da UFSC, Florianópolis. 160p.

Clark, L.G. 1992. Chusquea sect. Swallenochloa (Poaceae: Bambusoideae) and allies in Brazil. Brittonia 44: 387-422.

Clark, L.G. \& Blong, A. 2009. Anew species of Chusquea sect. Swallenochloa (Poaceae: Bambusoideae: Bambuseae) from Brazil. Bamboo Science and Culture: The Journal of the American Bamboo Society 22: 26-31.

Filgueiras, T.S \& Santos-Gonçalves, A.P. 2004. A checklist of the basal grasses and bamboo in Brazil (Poaceae). Bamboo Science and Culture: the Journal of the American Bamboo Society 18: 7-18.

Filgueiras, T.S. \& Santos-Gonçalves, A.P. 2007. TupiGuarani: fonte de informações sobre bambus nativos do Brasil. Heringeriana 1: 35-41.
Hickey, M. \& King, C. 2000. The Cambridge illustrated glossary of botanical terms. Cambridge University Press, Cambridge. 208p.

Horn Filho, N.O. 2004. Estudos morfosedimentares (19702004) nas praias da Ilha de Santa Catarina, SC, Brasil, uma síntese. Gravel 2: 57-70.

Judziewicz, E.J.; Clark, L.G.; Londoño, X. \& Stern, M.J. 1999. American Bamboos. Smithsonian Institution Press, Washington. 392p.

McClure, F.A. \& Smith, L.B. 1967. Gramíneas Suplemento Bambúseas. In: Reitz, R. (ed.). Flora Ilustrada Catarinense. Herbário Barbosa Rodrigues, Itajaí. Pp. 1-78.

Mori, S.A.; Silva, L.A.M.; Lisboa, G. \& Coradin, L. 1989. Manual de manejo do herbário fanerogâmico. CEPLAC, Ilhéus. 104p.

Ohrnberger, D. 1999. The bamboos of the world: annotated nomenclature and literature of the species and the higher and lower taxa. Elsevier Science B.V., Amsterdam. 584p.

Radford, A.E.; Dickison, W.C.; Massey, J.R. \& Bell, C.R. 1974. Vascular plant systematics. Harper \& Row, New York. 891p.

Shirasuna, R.T. \& Filgueiras, T.S. 2013. Bambus nativos (Poaceae, Bambusoideae) no Parque Estadual das Fontes do Ipiranga, São Paulo, SP, Brasil. Hoehnea 40: 315-359.

Silva, C.; Silva Conde, M.M. \& Longhi-Wagner, H.M. 2012. Olyreae (Poaceae: Bambusoideae) da Marambaia, Rio de Janeiro, Brasil. Rodriguésia 63: 357-372.

Smith, L.B.; Wasshausen, D.C. \& Klein, R.M. 1981. Gramíneas. In: Reitz, R. (ed.). Flora Ilustrada Catarinense. Herbário Barbosa Rodrigues, Itajaí. Pp. 27-198.

Soderstrom, T.R. \& Zuloaga, F.O. 1989. A revision of the genus Olyra and the new segregate genus Parodiolyra (Poaceae: Bambusoideae: Olyreae). Smithsonian Contributions to Botany 69: 1-79.

Soreng, R.J.; Peterson, P.M.; Romaschenko, K.; Davidse G.; Zuloaga, F.O.; Judziewicz E.J.; Filgueiras, T.S.; Davis, J.I. \& Morrone, O. 2015. A worldwide phylogenetic classification of the Poaceae (Gramineae). Journal of Systematics and Evolution 53: 117-137.

Thiers, B. [continuosly updated]. Index Herbariorum: A global directory of public herbaria and associated staff. New York Botanical Garden's Virtual Herbarium. Disponível em $<$ http://sweetgum.nybg. org/ih/> . Acesso em 23 fevereiro 2016.

Viana, P.L.; Filgueiras, T.S. \& Clark, L.G. 2013. Cambajuva (Poaceae: Bambusoideae: Bambuseae: Arthrostylidiinae), a new woody bamboo genus from Southern Brazil. Systematic Botany 38: 97-103.

Zhang, W. \& Clark, L.G. 2000. Phylogeny and classification of the Bambusoideae (Poaceae). In: Jacobs, S.W.L. \& Everett, J.E. (eds.). Grasses: systematics and evolution. CSIRO, Collingwood. Pp. 35-42. 


\section{Lista de exsicatas}

Os números entre parênteses correspondem às seguintes espécies: 1. Olyra glaberrima; 2. Olyra humilis; 3. Olyra latifolia; 4. Parodiolyra micrantha; 5. Reitzia smithii.

Amorim et al. 764 MBM(4). Barbosa \& Cordeiro 495 MBM(4). Bernacci 2164 SP(2). Bresolin 307, 314 FLOR(4), 1321 FLOR(5). Bresolin \& Klein 1352 FLOR(2). Calderón 2002 MBM(5). Campestrini 198 FLOR(4). Carneiro 771 MBM(2). Catharino et al. 1553 SP(1). Cemin s.n. CRI 7685(2), CRI 7664(3). Clayton 4871 SP(2). Dombrowski 13456 MBM(4). Dombrowski \& Scherer Neto 12035 MBM(1), 7517 MBM(4), 10762 FLOR, MBM(4). Falkenberg \& Leonor Souza 3208 FLOR(3). Forzza et al. 1882 FLOR(4). Garcia et al. 677 SP(1). Gibbs \& Leitão Filho 6098 MBM(4). Greco 47, 68, 76, 104, 142 FLOR(1), 94,130, 135,143 FLOR(2), 23, 49, 72, 86, 106, 117 FLOR(3), 13, 14, 16, 44, 85, 99, 112, 118, 131, 132, 144,145, 147 FLOR(4), 120 FLOR(5). Greco \& Ardissone 133 FLOR(4). Greco \& Zannin 5 FLOR(2). Hatschbach 22340 MBM(2), 43954 FLOR, MBM(3). Hatschbach \& Cervi 50650 MBM(2). Jarenkow \& Waechter 1657 FLOR(3). Klein 6968 FLOR, MBM(1), 7001 MBM(1), 9814 HBR, MBM(1), 9672, 10204 FLOR(4), 9529 FLOR, MBM(5), 11768 CRI, FLOR(5). Klein et al. 11916 FLOR(2), 7950 FLOR(3), 7950 FLOR(4), 6812 FLOR(5). Klein \& Bresolin 8766 FLOR, MBM(2), 11580 FLOR(2), 6244, 8355 FLOR(4), 8399 CRI, FLOR, HBR(4), 6880 FLOR(5). Klein \& Souza Sobrinho 10519 FLOR(4). Klink 16649 UEC(2). Kuhlmann 113 SP(1). Leonor Souza et al. 313 FLOR(4). Mello et al. 517 FLOR(2), 485 FLOR(4). Nicolau et al. 1475 SP(1). Nuernberg \& Mello 552 FLOR(4). Pugues et al. 108 FLOR(2). Queiroz 199 FLOR(3), 253, 268,334 FLOR(4). Reitz 5939 FLOR, MBM(5). Ribas et al. 4435 MBM(1). Rocha s.n. CRI 7430(2). Roderjan \& Jaster 1304 MBM(1). Silva 97 FLOR(1). Silva et al. 242 FLOR, SP(4). Silva \& Zannin 972 FLOR(2). Smith \& Reitz 12529 FLOR(2). Souza et al. 18539 ESA, FLOR(4). Souza \& Kinupp 30585 ESA(3). Sugiyama 1272 SP(1). Sugiyama \& Rossi 1137 FLOR, SP(4). Warmling 32 FLOR (1). Zannin 1529, 1618 FLOR(4). Zannin et al. 1596 FLOR(4). 